\title{
Recommendations of the Brazilian Society of Hepatology for the management of acute kidney injury in patients with cirrhosis
}

\author{
Carlos TERRA ${ }^{1,2}$, Ângelo Zambam de MATTOS $^{3}$, Gustavo PEREIRA ${ }^{4}$, Alberto Queiroz FARIAS ${ }^{5}$, \\ Mario KONDO6 ${ }^{6}$, Angelo Alves de MATTOS 3 , José Eymard Moraes de MEDEIROS FILHO, \\ Edna STRAUSS ${ }^{8}$, Fábio Ricardo Dantas DUTRA ${ }^{9}$, Marcelo MAZZA ${ }^{10}$, Edmundo Pessoa LOPES ${ }^{11}$, \\ Tiago SEVÁ PEREIRA ${ }^{12}$, Leonardo Lucca SCHIAVON ${ }^{13}$, Roberto José de CARVALHO FILHO ${ }^{14}$, \\ Cláudia FAGUNDES ${ }^{15,16}$ and Paulo Lisboa BITTENCOURT ${ }^{17}$
}

Received 6/5/2018 Accepted 11/6/2018

\begin{abstract}
Acute kidney injury is a common complication of cirrhosis, occurring in up to $20 \%$ of patients hospitalized with cirrhosis. This field is rapidly changing, with significant advances in classification, biomarkers and therapy over the last few years. On the behalf of the Brazilian Society of Hepatology, a panel of experts in Hepatology and Nephrology reviewed published evidence to integrate findings and develop the recommendations presented in this manuscript.
\end{abstract}

HEADINGS - Acute kidney injury. Disease management. Liver cirrhosis, complications. Risk assessment.

\section{INTRODUCTION}

Acute kidney injury (AKI) is a common complication of cirrhosis, occurring in up to $20 \%$ of patients hospitalized with cirrhosis $^{(1)}$. There are many reasons for the development of AKI in cirrhotic patients, such as: i) infections; ii) hypovolemia (loss of fluids associated with bleeding, use of diuretics or gastrointestinal losses); iii) parenchymal nephropathy, iv) nephrotoxicity (drug-induced or contrast-induced nephropathy); v) hepatorenal syndrome - $(\mathrm{HRS})^{(2-4)}$. A large study of 463 hospitalized cirrhotic patients with AKI evaluated the frequency and the prognosis of the different etiologies of AKI. This study demonstrated that the most frequent cause of AKI among cirrhotic patients was bacterial infection (46\%), followed by volume depletion (32\%), HRS (13\%) and parenchymal nephropathy ( $9 \%)$. Among infections, spontaneous bacterial peritonitis (SBP) and spontaneous bacteremia were the most common, although almost any type of infection could lead to AKI because of the aggravation of circulatory dysfunction commonly found in cirrhosis. The 90-day mortality for the whole series was high $(60 \%)$, but it was particularly high among patients with AKI associated with infections or $\mathrm{HRS}^{(2)}$. In a multivariate analysis adjusted for potentially confounding variables, the cause of AKI was independently associated with prognosis. The same findings were also reported in another study from Brazil ${ }^{(4)}$. Not only AKI but also the etiology of AKI seems to play an important role in the prognosis of cirrhotic patients who develop AKI. In this context, the worst outcomes for patients with AKI are associated with HRS or infection.

\section{DIAGNOSTIC CRITERIA}

Serum creatinine ( $\mathrm{SCr}$ ), an endogenous biomarker, is traditionally used to evaluate renal function ${ }^{(5)}$. Nevertheless, $\mathrm{SCr}$ level may be affected by a number of factors. In cirrhosis, $\mathrm{SCr}$ may still be in the normal range despite significant reductions in renal function because of protein-calorie malnutrition and cirrhosis-related sarcopenia. Sudden changes in renal function may not be accurately evaluated by $\mathrm{SCr}$, which takes time to rise. Another limiting factor for the interpretation of $\mathrm{SCr}$ as a biomarker is the laboratory method employed for its determination ${ }^{(6,7)}$. It is also noteworthy that high levels of bilirubin in the blood may lead to a reduction in $\mathrm{SCr}$ levels ${ }^{(8)}$.

The combination of lower production of creatine, higher tubular secretion of creatinine and presence of malnutrition may contribute to a misleadingly lower than expected levels of SCr in cirrhotic patients. Therefore, methods of evaluation of renal function based on $\mathrm{SCr}$ must be carefully interpreted in this context.

Declared conflict of interest of all authors: none

Disclosure of funding: no funding received

${ }^{1}$ Universidade do Estado do Rio de Janeiro, Faculdade de Medicina, Departamento de Gastroenterologia, RJ, Brasil. ${ }^{2}$ Hospital Federal de Lagoa, Departamento de Gastroenterologia, Rio de Janeiro, RJ, Brasil. ${ }^{3}$ Universidade Federal de Ciências da Saúde de Porto Alegre, Programa de Pós-Graduação em Medicina: Hepatologia, RS, Brasil. ${ }^{4}$ Hospital Federal de Bonsucesso, Serviço de Gastroenterologia e Hepatologia, Rio de Janeiro, RJ, Brasil. ${ }^{5}$ Universidade de São Paulo, Faculdade de Medicina, Departamento de Gastroenterologia, SP, Brasil. ${ }^{6}$ Universidade Federal de São Paulo, Faculdade de Medicina, Departamento de Gastroenterologia, SP, Brasil. ${ }^{7}$ Universidade Federal da Paraíba, Centro de Ciências Médicas, Departamento de Medicina Interna, João Pessoa, PB, Brasil. ${ }^{8}$ Universidade de São Paulo, Faculdade de Medicina, Departamento de Patologia, SP, Brasil. ${ }^{9}$ Hospital Português, Departamento de Nefrologia, Salvador, BA, Brasil. ${ }^{10}$ Universidade Federal do Paraná, Faculdade de Medicina, Departamento de Nefrologia, Curitiba, PR, Brasil. ${ }^{11}$ Universidade Federal de Pernambuco, Faculdade de Medicina, Departamento de Medicina Clínica, Recife, PE, Brasil. ${ }^{12}$ Universidade Estadual de Campinas, Faculdade Ciências Médicas, Disciplina de Gastroenterologia, Campinas, SP, Brasil. ${ }^{13}$ Universidade Federal de Santa Catarina, Faculdade de Medicina, Departamento de Clínica Médica, Florianópolis, SC, Brasil. ${ }^{14}$ Universidade Federal de São Paulo, Hospital São Paulo, SP, Brasil. ${ }^{15}$ Hospital Federal de Bonsucesso, Serviço de Nefrologia, Rio de Janeiro, RJ, Brasil. ${ }^{16}$ Hospital São Francisco, Unidade de Transplante Renal, Rio de Janeiro, RJ, Brasil. ${ }^{17}$ Hospital Português, Unidade de Gastroenterologia e Hepatologia, Salvador, BA, Brasil.

Corresponding author: Alberto Queiroz Farias. Orcid: 0000-0002-5572-663X. E-mail: albertofarias@terra.com.br, albertogfarias@gmail.com 
There is a body of evidence suggesting that the traditional definition of AKI, based on a fixed cut-off point of SCr above 1.5 $\mathrm{mg} / \mathrm{dL}$, poorly reflects the dynamic changes in renal function of cirrhotic patients in different clinical situations ${ }^{(9-13)}$. In this context, a study demonstrated that the maximum value of SCr associated with normal renal function in cirrhotic patients would be $1 \mathrm{mg} / \mathrm{dL}$. Values of $\mathrm{SCr}$ between $1.0 \mathrm{mg} / \mathrm{dL}$ and $1.5 \mathrm{mg} / \mathrm{dL}$ were suggestive of renal failure and were associated with lower survival ${ }^{(13)}$, while values above $1.5 \mathrm{mg} / \mathrm{dL}$ were associated with severe AKI with a high specificity. There are studies that suggest that mild elevations of $\operatorname{SCr}(\geq 0.3 \mathrm{mg}$ ) dL) are associated with significant changes in GFR of cirrhotic patients, and are independently associated with higher incidence of organ dysfunction (OD), longer hospitalization and higher mortality, both in the general population and in cirrhotic patients ${ }^{(9,12-15)}$.

In 2004, the Risk Injury Failure Loss of Kidney Function and End-Stage Kidney Disease (RIFLE) criteria standardized a new definition of AKI based on the variation of SCr, GFR and urine output $^{(16)}$. RIFLE was innovative because it allowed the staging of patients according to their prognosis. Until then, there were many different definitions of AKI, which complicated comparison of data in distinct studies. In 2007, the Acute Kidney Injury Network (AKIN), a network of nephrologists and critical care physicians dedicated to studying AKI, recognized that mild variations of $\mathrm{SCr}(0.3 \mathrm{mg} / \mathrm{dL}$ in 48 hours) were related to worse prognosis and should be taken into consideration $^{(17)}$. Following this, the Kidney Disease Improving Global Outcomes (KDIGO) classification combined concepts from both previous classifications ${ }^{(18)}$. Recently, the International Club of Ascites (ICA) used this classification to recommend new diagnostic criteria for AKI in cirrhotic patients ${ }^{(19)}$. In this new classification, the ICA-AKI criteria, absolute cut-off points of SCr were abolished, criteria based on urine output were eliminated (urine output is considered an imprecise parameter in cirrhotic patients), and three stages of AKI were defined based on the magnitude of the dynamic changes of SCr compared to baseline (FIGURE 1).

\begin{tabular}{|c|c|}
\hline \multicolumn{2}{|c|}{ Definition of AKI } \\
\hline \multicolumn{2}{|c|}{$\begin{array}{l}\text { Increase in } \mathrm{SCr} \geq 0.3 \mathrm{mg} / \mathrm{dL} \text { within } 48 \text { hours compared to } \\
\text { baseline*; or }\end{array}$} \\
\hline \multicolumn{2}{|c|}{$\begin{array}{l}\text { Increase in } \mathrm{SCr} \geq 50 \% \text { (known or presumed to have } \\
\text { occurred during the previous } 7 \text { days) }\end{array}$} \\
\hline \multicolumn{2}{|c|}{ Staging of AKI } \\
\hline \multirow{2}{*}{ Stage 1} & Increase in $\mathrm{SCr} \geq 0.3 \mathrm{mg} / \mathrm{dL}$; or \\
\hline & Increase $\geq 1.5 x-2.0 x$ from baseline. \\
\hline Stage 2 & Increase in SCr $>2.0 x-3.0 x$ from baseline. \\
\hline \multirow{3}{*}{ Stage 3} & Increase in $\mathrm{SCr}>3.0 x$ from baseline; or \\
\hline & $\begin{array}{l}\mathrm{SCr} \geq 4.0 \mathrm{mg} / \mathrm{dL} \text { with an acute increase } \\
\geq 0.3 \mathrm{mg} / \mathrm{dL} \text {; or }\end{array}$ \\
\hline & $\begin{array}{l}\text { AKI with indication of renal replacement } \\
\text { therapy. }\end{array}$ \\
\hline
\end{tabular}

FIGURE 1. Definitions of acute kidney injury in cirrhotic patients according to the recommendations of the International Club of Ascites ${ }^{(20)}$. AKI: acute kidney injury. SCr: serum creatinine. *Serum creatinine value closest to hospital admission, within 3 months. In the absence of a previous creatinine value, serum creatinine at admission should be considered baseline.
After the recommendation of the new diagnostic criteria for AKI in cirrhosis ${ }^{(9-12)}$, some studies suggested that patients with mild AKI (stage 1) and maximum SCr $<1.5 \mathrm{mg} / \mathrm{dL}$ have more favorable outcomes, similar to those of patients who do not have AKI ${ }^{(10,11,20)}$. Nevertheless, it should be noticed that these studies evaluated only short term prognosis, and did not consider the impact of mild AKI on longer term mortality. Besides, the etiology of AKI, which is associated with different prognoses ${ }^{(2)}$, was not considered in these studies. Important outcomes, such as occurrence of other complications of cirrhosis, recurrence of AKI and rate of hospital readmission, also were not evaluated. Therefore, additional studies are needed in order to define the possible prognostic contribution of a mixed model of glomerular function evaluation in cirrhotic patients, considering the traditional cut-off point of $\mathrm{SCr}$ of 1.5 $\mathrm{mg} / \mathrm{dL}$ as well as the dynamic changes in SCr proposed by the ICA-AKI classification.

Another application of longitudinal monitoring of SCr involves the evaluation of response to therapeutic measures. Three patterns of response were proposed by $\mathrm{ICA}^{(19)}$ : 1) No response: no reduction of SCr; 2) Partial response: regression of at least one stage of AKI, but minimum level of $\mathrm{SCr}$ persists at least $0.3 \mathrm{mg} / \mathrm{dL}$ above the baseline; 3) Full response: reduction of $\mathrm{SCr}$ to levels close to baseline $(<0.3 \mathrm{mg} / \mathrm{dL}$ above the baseline).

The new ICA-AKI definition of AKI in cirrhosis corrects, even if not completely, some of the problems related to using $\mathrm{SCr}$ as a biomarker of renal function. It considers baseline $\mathrm{SCr}$, and enables earlier diagnosis of AKI from mild changes in SCr levels. Nevertheless, it does not consider the etiology of AKI, which crucially limits its impact on therapeutic decision-making, since treatment of AKI varies according to its cause. Therefore, there is still a need for studying other biomarkers capable of considering the etiology of AKI and aiding early treatment decisions.

\section{Biomarkers}

Among the biomarkers studied in the context of AKI, the most extensively evaluated in cirrhotic patients at present is Neutrophil Gelatinase-Associated Lipocalin (NGAL). NGAL is an inflammatory biomarker produced by damaged renal tubular cells (as well as from leukocytes and hepatocytes). Its concentration in urine varies according to the etiology of AKI in cirrhosis ${ }^{(21)}$. Among patients with AKI, those with pre-renal AKI present the lowest values of urinary NGAL (median $30 \mu \mathrm{g} / \mathrm{g}$ ), while patients with acute tubular necrosis (ATN) have much higher levels of urinary NGAL (median $417 \mu \mathrm{g} / \mathrm{g}$ ). Patients with HRS present intermediate levels of urinary NGAL (median $76 \mu \mathrm{g} / \mathrm{g}$ ). Moreover, urinary NGAL predicts significant outcomes in cirrhotic patients.

A Brazilian pilot study demonstrated that, among nine patients with cirrhosis and bacterial infection, urinary NGAL predicted the development of AKI before the traditional criteria used in cirrhosis $^{(22)}$. It is noteworthy that despite the diagnosis of AKI according to SCr being made after a mean of 5.4 days after admission, urinary levels of NGAL in those patients increased as early as 6 hours from hospital admission.

Other studies verified an association between urinary NGAL and the clinical course of AKI or 90-day mortality ${ }^{(23,24)}$. Therefore, measurement of urinary NGAL seems promising for clinical practice, since it could predict relevant clinical outcomes in cirrhotic patients and possibly assist therapeutic decision-making as it could identify the cause of AKI at an early stage. 


\section{Diagnosis of hepatorenal syndrome}

HRS is a severe complication occurring in patients with cirrhosis and ascites, with an annual incidence around $18 \%{ }^{(2)}$. It is characterized by renal vasoconstriction, reduction of renal perfusion and diminished GFR, which causes a significant decrease in the kidney's capacity to excrete sodium and free water, in the absence of major renal histological damage ${ }^{(26)}$. The absence of significant histological damage and the recovery of renal function after liver transplantation define the functional characteristics of the syndrome. HRS is the complication of cirrhosis which presents the worst prognosis, having a median survival of around two weeks if left untreated ${ }^{(27)}$. Therefore, it was long considered a terminal event in the course of cirrhosis. The introduction of treatments that are effective in reversing HRS led to improvement of short-term survival, allowing a significant number of these patients to reach liver transplantation, which is considered the definitive treatment for patients with end-stage liver disease.

Because of the lack of specific tests for HRS, its diagnosis requires exclusion of other causes of AKI in patients with cirrhosis and ascites. The exclusion of acute tubular necrosis (ATN) as a cause of AKI is especially important, since HRS and ATN have different management strategies and prognoses. ATN usually occurs in patients with septic or hypovolemic shock, being characterized by the presence of epithelial cells and granular casts in the urinary sediment analysis, as well as by high urinary excretion of sodium (urinary sodium $>40 \mathrm{mEq} / \mathrm{L}$ and sodium excretion fraction $>2 \%$ ) and low urinary osmolarity $(<350 \mathrm{mOsm} / \mathrm{kg})$. Conversely, patients with HRS do not present alterations in urinary sediment and maintain high capacity of tubular reabsorption of sodium and free water, with values of urinary sodium and sodium excretion fraction under $20 \mathrm{mEq} / \mathrm{L}$ and $1 \%$ respectively, as well as high urinary osmolarity $(>500 \mathrm{mOsm} / \mathrm{kg})^{(28)}$. The diagnosis of HRS currently must be performed according to the criteria presented in FIGURE 2.

\section{Cirrhosis and ascites}

Acute kidney injury according to the new International Club of Ascites criteria (see FIGURE 1).

\section{Absence of structural renal injury, suggested by} proteinuria ( $>500 \mathrm{mg} / 24$ hours), hematuria ( $>50$ red blood cells/high power field) and/or renal alterations on ultrasonography.

Absence of renal function recovery (return of serum creatinine to a final value up to $0.3 \mathrm{mg} / \mathrm{dL}$ above the baseline) after two consecutive days of diuretic withdrawal and plasma volume expansion with albumin $(1 \mathrm{~g} / \mathrm{Kg} / \mathrm{day}$, up to a maximum of $100 \mathrm{~g} /$ day).

\section{Absence of shock}

Absence of current or recent use of nephrotoxic drugs (aminoglycosides, non-steroidal anti-inflammatory drugs, among others).

FIGURE 2. Diagnostic criteria for hepatorenal syndrome-acute kidney injury ${ }^{(19)}$.
The most important change introduced by the new criteria is allowing earlier treatment of HRS, since, according to the previous criteria, the diagnosis could only be done and the treatment initiated if there was a 2 -fold increase in $\mathrm{SCr}$ to a value $\geq 2.5 \mathrm{mg} / \mathrm{dL}$ within two weeks. The probability of treatment response in HRS is inversely proportional to the value of $\mathrm{SCr}$ when treatment begins. This suggests that prognosis is associated with the magnitude of AKI and the promptness of diagnosis, more sensitive criteria were in $\operatorname{order}^{(29)}$.

In 1996, ICA classified HRS in two types ${ }^{(30)}$. HRS type 1 (HRS1) was characterized by severe and rapidly progressive renal failure, defined by a two-fold increase in SCr to a level $\geq 2.5 \mathrm{mg} / \mathrm{dL}$ within two weeks. Even though HRS-1 could develop spontaneously, it frequently follows a precipitating factor, such as bacterial infection, gastrointestinal bleeding, major surgical intervention or acute hepatitis occurring in a cirrhotic patient. HRS type 2 (HRS-2) is characterized by moderate and steady or slowly progressive decrease in renal function, accompanied by signs of liver failure and arterial hypotension to a lesser degree than in patients with HRS-1. The dominant clinical characteristic of patients with HRS-2 is tense ascites with poor response to diuretic therapy; refractory ascites. It is noteworthy that patients with HRS-2 are particularly susceptible to developing HRS-1. Median survival of patients with HRS-2 (6 months) is significantly lower than that of cirrhotic patients with ascites and preserved renal function ${ }^{(30)}$. After the adoption of the ICA-AKI criteria for defining HRS (FIGURE 2), the nomenclature of hepatorenal syndrome-acute kidney injury (HRS-AKI) is preferred to HRS-1 and HRS-2.

Recently, new concepts of HRS-2 are being proposed ${ }^{(31)}$, raising the possibility that it is a functional chronic kidney disease, in which case it would be considered for patients with a GFR under $60 \mathrm{~mL} /$ minute/ $1.73 \mathrm{~m}^{2}$ for over three months. It should be distinguished from organic chronic kidney disease. This distinction is of particular importance with the increasing prevalence of non-alcoholic fatty liver disease related to metabolic syndrome as a major worldwide cause of chronic liver disease. It is frequently associated with diabetes and systemic arterial hypertension, both well-documented causes of renal damage.

\section{Recommendations}

A. ICA-AKI criteria should be used for the diagnosis and staging of AKI in patients with cirrhosis.

B. Following diagnosis of AKI, the identification of its underlying cause should be pursued in order to manage the condition properly, with favorable impact on prognosis.

C. Using biomarkers for the diagnosis of AKI, although promising, is not currently supported by enough scientific evidence and still cannot be recommended for routine clinical practice.

D. Diagnosis of HRS should be based on HRS-AKI criteria, which allows early indication of therapeutic measures.

\section{TREATMENT OF AKI IN CIRRHOSIS}

\section{General measures}

Following the diagnosis of AKI, etiology should be determined in order to define the appropriate treatment. In this context, the recently revised recommendations of the ICA are the following ${ }^{(19)}$ :

- Rule out parenchymal renal disease (investigate hematuria, proteinuria or microalbuminuria, and perform a urinary system ultrasound); 
- Rule out drug-induced AKI (aminoglycoside antibiotics, non-steroidal anti-inflammatory drugs, vasodilatory drugs, beta-blockers or iodinated contrast media);

- Withdraw or reduce the dosage of diuretics and perform volume expansion in order to rule out prerenal azotemia;

- Consider ATN in the presence of shock;

- Actively investigate infections, especially SBP, and begin early empirical antibiotic treatment if infection is suspected.

Renal function frequently normalizes after the correction of the precipitating factor, especially in initial stages. When kidney injury progresses despite the initial treatment or when AKI is diagnosed at more advanced stages (ICA-AKI stages 2 or 3 ), volume expansion with albumin $1 \mathrm{~g} / \mathrm{Kg}$ /day for 48 hours is recommended. This must be done carefully, since oliguria is frequent in cirrhosis, and may lead to pulmonary edema. When renal function fails to improve even after volume expansion with albumin and if other causes of kidney injury have been excluded, specific treatment for HRS should be considered.

\section{Albumin}

There is robust evidence demonstrating the importance of albumin in the context of decompensated cirrhosis. Initially, the lack of response to volume expansion with albumin should be remembered as a prerequisite for the diagnosis of HRS in cirrhotic patients with $\mathrm{AKI}^{(32)}$. Albumin is capable of preventing loss of renal function in patients submitted to large volume paracentesis, a benefit not seen with other plasma expanders ${ }^{(33)}$. There is also evidence that albumin improves renal autoregulation curves both in cirrhotic patients with AKI and in those with ascites and normal renal function ${ }^{(34)}$. In patients with $\mathrm{HRS}$, response to terlipressin is significantly better when it is co-administered with albumin ${ }^{(35)}$. In patients with SBP, albumin use in conjunction with antibiotic treatment significantly reduces the incidence of HRS and in-hospital mortality, effects which were not identified using hydroxyethyl $\operatorname{starch}^{(36,37)}$

Some studies evaluated the role of albumin infusion in both prevention and treatment of AKI in infected cirrhotic patients ${ }^{(36,38,39)}$. A randomized controlled trial ${ }^{(36)}$ demonstrated that use of albumin with the antibiotic treatment of SBP led to a lower incidence of AKI when compared to using antibiotics alone. Similarly, in-hospital and 3-month mortalities were significantly lower in patients who received albumin. In that study, albumin was administered at two distinct times: on the day of diagnosis of SBP (D1) patients received $1.5 \mathrm{~g} / \mathrm{Kg}$ of albumin and a second infusion of $1 \mathrm{~g} / \mathrm{Kg}$ on the third day after diagnosis ${ }^{(36)}$.

Recently, a randomized controlled trial analyzed the effects of albumin on 110 cirrhotic patients with infections other than $\mathrm{SBP}^{(38)}$. Albumin, used in similar doses recommended for SBP, led to an improvement of circulatory and renal functions and had a positive impact on survival when the analysis was controlled for other variables which were independently associated with prognosis. Another study ${ }^{(39)}$ showed that albumin infusion was able to postpone the occurrence of AKI, but unable to increase survival. Even though this still is an open question, it is possible that there are benefits of albumin for infections severe enough to negatively affect circulatory function.

\section{Vasoconstrictors}

Use of a vasoconstrictor in combination with albumin for the treatment of HRS has been suggested since the $1990 \mathrm{~s}^{(40)}$. The most common drugs are terlipressin (an analogue of vasopressin) and noradrenaline (an adrenergic agonist). A combination of midodrine and octreotide was recently shown to be less effective than terlipressin in the treatment of $\mathrm{HRS}^{(41)}$.

Terlipressin is administered as an intravenous bolus infusion, initially in doses of $0.5-1.0 \mathrm{mg}$ each 4-6 hours. Treatment response should be evaluated in intervals of 48 hours. In the absence of at least $25 \%$ decrease in $\mathrm{SCr}$ after the first 48 hours, terlipressin doses could be gradually increased every two days up to the maximum dosage of $12 \mathrm{mg} /$ day. Treatment is maintained for up to 14 days, but the drug can be discontinued earlier in cases of poor response (less than $50 \%$ decrease in SCr after seven days of terlipressin at its highest dose or no reduction in $\mathrm{SCr}$ after the first three days of therapy ${ }^{(3,19)}$. Terlipressin was associated with HRS reversal in 34\%-44\% of patients treated in two international randomized controlled trials ${ }^{(42,43)}$. In addition a meta-analysis demonstrated its association with HRS reversal, renal function improvement and decreased mortality ${ }^{(44)}$. When used in continuous infusion, lower doses of terlipressin may be administered, with fewer side effects and without significant loss of effectiveness, compared to bolus infusion ${ }^{(45)}$.

Continuous noradrenaline infusion, in doses of $0.5-3.0 \mathrm{mg} /$ hour, was also associated with HRS reversal, in a similar way to that seen with terlipressin. Even though evidence is scarcer than for terlipressin, noradrenaline is considered to be a valid alternative for the treatment of HRS because of its similar effectiveness, wide availability ${ }^{(46)}$. Although the drug itself is cheaper, the treatment strategy using noradrenaline for HRS is actually more expensive than a strategy using terlipressin once direct medical costs are included. This is mostly because noradrenaline use requires admission to an intensive care unit, and terlipressin use does not, as shown by a recent Brazilian study ${ }^{(47,48)}$.

Treatment of HRS with a vasoconstrictor and albumin may lead to adverse events in approximately $10 \%$ of patients. These effects are usually ischemic (mostly affecting the heart, gut and lower limbs) or related to pulmonary edema. They are managed with drug dose reduction; complete withdrawal of treatment is seldom needed.

Treatment indication for HRS must take into account the stage of AKI according to ICA-AKI criteria. Patients with HRS and ICA-AKI stages 2 or 3 should be immediately managed with a vasoconstrictor and albumin. Treatment for patients at stage 1 should be tailored. Because of the high short-term mortality, treatment should be considered carefully for patients at stage $1 \mathrm{~b}$. For those at stage 1a, renal function should be closely monitored, potentially aggravating factors should be avoided, and treatment should be reserved for patients whose AKI progresses to higher stages.

\section{Treatment of HRS-2}

Based on the fact that HRS-2 occurs in a context of advanced cirrhosis, the gold standard treatment is liver transplantation. Studies evaluating the role of vasoconstrictors for HRS-2 ${ }^{(49,50)}$ gathered small samples of patients and frequently combined HRS-1 and -2. As a general rule, these studies suggested that HRS-2 reversal is more common when a vasoconstrictor is used than in control groups. Nevertheless, the quality of evidence is too low to recommend treatment. A study evaluating treatment of HRS-2 in patients on the liver transplant waiting list ${ }^{(51)}$ was unable to demonstrate that HRS reversal with terlipressin and albumin ultimately influenced the prognoses of the patients. Recurrence rate after treatment interruption is high, around $40 \%{ }^{(52)}$. Therefore, treatment of HRS-2 with a vasoconstrictor still requires more randomized controlled trials clearly showing its benefits in order for it to be formally recommended. At this moment, it is considered a treatment to be used in exceptional circumstances, 
possibly recommended for patients who are expected to receive a liver transplant a short time after.

Even though transjugular intrahepatic portosystemic shunt (TIPS) seems to improve renal function ${ }^{(53,54)}$, its role in HRS-2 treatment remains speculative. Therefore, it might be indicated only in very well selected cases.

The best therapeutic option for these patients is liver transplantation. Despite patients with HRS usually needing more blood components, spending more time in the intensive care unit and having longer hospitalizations, 1-year survival is similar to that of patients with normal renal function ${ }^{(55)}$.

\section{Recommendations}

A. The diagnosis of HRS requires ruling out other causes of AKI in cirrhosis, especially ATN.

B. The administration of intravenous albumin is recommended for patients with SBP for HRS prophylaxis, and the recommended dose is $1.5 \mathrm{~g} / \mathrm{Kg}$ at the first day and $1.0 \mathrm{~g} / \mathrm{Kg}$ at the third day of treatment. More studies are needed in order to assess its role in infections other than SBP.

C. The association of a vasoconstrictor (preferably terlipressin) and albumin is the treatment of choice for HRS.

D. The treatment for HRS is recommended for patients with HRS-AKI stages 2 or 3, independently of the values of SCr at the time of diagnosis. Ttreating patients with HRS-AKI stage $1 \mathrm{~b}$ should be considered if SCr increases at least 50\% over the baseline.

E. Liver transplantation is the treatment of choice for patients with HRS-2. The use of a vasoconstrictor and albumin should be tailored, taking into account the probability of, and time to transplantation.

\section{Renal replacement therapy}

Renal replacement therapy (RRT) should be considered for severe AKI, particularly those patients on the waiting list for liver transplantation or where recovery of liver function is anticipated.

The indication for RRT follows standard guidelines and it is not specific for patients with cirrhosis and AKI. Conventional indications include volume overload, severe hyperkalemia, uremia (encephalopathy, pericarditis), severe metabolic acidosis and exogenous intoxication. In patients with HRS, RRT should be indicated in the absence of response or adverse reaction to vasoconstrictors. The assessment of prognosis, eligibility for liver transplantation, advanced stages of acute on chronic liver failure (ACLF), should be considered before RRT to avoid futile treatments. Ideal timing to begin RRT is still controversial. Patients that do not fit in conventional indications should be judged on a case-by-case basis.

The choice of the dialytic method is critical for in decompensated cirrhosis or ACLF patients. Worsening of circulatory dysfunction (i.e. severe arterial hypotension) during RRT is a major concern as it may cause organ failure. RRT is particularly poorly tolerated in patients with HRS, due to the profound hemodynamic disturbance that are characteristic of this syndrome.

Acceptable RRT methods are intermittent both conventional hemodialysis or peritoneal dialysis; continuous hemofiltration or continuous hemodiafiltration; prolonged hemodialysis (SLED Sustained Low Efficiency Dialysis). SLED has the advantage of providing cardiovascular stability and effective clearance of continuous therapies, with the reduced costs of intermittent therapies ${ }^{(56)}$.

The most important limiting factor of intermittent therapies is hemodynamic instability. Hypotension during RRT is associated with dialysis technique (volume and ultrafiltration rate, reduction of plasmatic osmolality) and patient characteristics (hypovolemia, vasodilation, liver failure $)^{(57,58)}$. Hypotension decreases the effectiveness of RRT and aggravates ischemic injury, delaying the recovery of kidney function ${ }^{(59)}$. When compared to intermittent therapies, continuous methods offer greater hemodynamic stability, and are often preferred for patients with arterial hypotension ${ }^{(60)}$.

Thrombocytopenia and coagulopathy would limit the use of heparin or other anticoagulants during RRT. However, these coagulation disorders found in patients with cirrhosis do not protect patients against thrombosis during RRT. Due to the reduced bloodflow continuous therapies often require the use of anticoagulation in the dialysis circuit.

Peritoneal dialysis should not be routinely used due to increased risk of infections. Use of dialysis solutions with bicarbonate for patients with hyperlactatemia and regional anticoagulation (only in dialysis circuit) for severe coagulopathy are recommended.

\section{Combined liver-kidney transplantation (CLKT)}

Liver-kidney transplantation would be the procedure of choice for patients with end-stage liver and kidney disease. Because of the negative impact on prognosis that renal failure has on liver transplantation recipients, CKLT is usually proposed for these patients. Besides, the postoperative worsening of kidney function is associated with higher morbidity and mortality ${ }^{(61,62)}$.

It is still difficult to identify with certainty which patients may benefit from CKLT. Even though HRS may be entirely reversible with isolated liver transplantation, some patients do not recover. It is likely that these patients have progressed to ATN, and will require long-term RRT and eventual CKLT.

However, it is believed that duration of RRT greater than 6 weeks is a reasonable criterion for eligibility for combined liver and kidney transplantation and this is the basis of the current guidelines.

According to Consensus guidelines published in $2008^{(63)}$, indications for CKLT in patients with AKI and/or HRS are $\mathrm{SCr}>2.0$ $\mathrm{mg} / \mathrm{d}$ and RRT for more than 8 weeks without evidence of renal function recovery.

The OPTN (Organ Procurement and Transplantation Network) proposed slightly different minimum criteria for CKLT in candidates for LT. This group propose CKLT for patients with prolonged AKI, defined by 1) RRT for over 6 weeks (two dialysis sessions per week for 6 weeks); 2) GFR $\leq 25 \mathrm{~mL} / \mathrm{min} / 1,73 \mathrm{~m}^{2}$ for over 6 weeks. Or 3 ) a combination of both criteria (GFR $\leq 25 \mathrm{~mL} / \mathrm{min} / 1,73 \mathrm{~m}^{2}$ for 3 weeks followed by 3 weeks in RRT). GRF may be calculated either by MDRD formula or by creatinine clearance ${ }^{(64)}$.

\section{Recommendations}

A. Indications of RRT in patients with cirrhosis are the same as those for other patients with renal dysfunction: volume overload, uremia, and severe acid-base and/or electrolyte disorders.

B. Method of RRT should be selected on the basis of the clinical condition of the patient, especially hemodynamic stability. Continuous or hybrid therapies should be the method of choice in patients with hemodynamic instability.

C. Patients with cirrhosis and AKI who require RRT for over 6-8 weeks should be considered for CKLT.

\section{Authors' contribution}

Terra C, Mattos AZ, Bittencourt PL: wrote the manuscript. Farias AQ: critically reviewed the manuscript. All authors participated in the panel and approved the manuscript. 
Terra C, Mattos ÂZ, Pereira G, Farias AQ, Kondo M, Mattos AA, Medeiros Filho JEM, Strauss E, Dutra FRD, Mazza M, Lopes EP, Sevá Pereira T, Schiavon LL, Carvalho Filho RJ, Fagundes C, Bittencourt PL. Recomendações da Sociedade Brasileira de Hepatologia para manejo da lesão renal aguda em pacientes com cirrose. Arq Gastroenterol. 2018,55(3):314-20.

RESUMO - A lesão renal aguda é uma complicação comum da cirrose, acometendo até $20 \%$ dos pacientes hospitalizados. Este tema está em rápida evolução devido aos importantes avanços em novas classificações, biomarcadores e tratamentos que ocorreram nos últimos anos. Em nome da Sociedade Brasileira de Hepatologia, um painel de especialistas em Hepatologia e Nefrologia revisou as evidência publicadas na literatura, integrando os diferentes resultados de estudos, para desenvolver a presente recomendação.

DESCRITORES - Lesão renal aguda. Gerenciamento clínico. Cirrose hepática, complicações. Medição de risco.

\section{REFERENCES}

1. Fede G, D’Amico G, Arvaniti V, Tsochatzis E, Germani G, Georgiadis D, et al. Renal failure and cirrhosis: a systematic review of mortality and prognosis. $\mathrm{J}$ Hepatol. 2012;56:810-18.

2. Martin-Llahi M, Guevara M, Torre A, Fagundes C, Restuccia T, Gilabert R, et al. Prognostic importance of the cause of renal failure in patients with cirrhosis. Gastroenterology. 2011;140:488-496.e4.

3. Bittencourt PL, Farias AQ, Terra C. Renal failure in cirrhosis: Emerging concepts. World J Hepatol. 2015;7:2336-43.

4. Carvalho GC, Regis Cde A, Kalil JR, Cerqueira LA, Barbosa DS, Motta MP, et al. Causes of renal failure in patients with decompensated cirrhosis and its impact in hospital mortality. Ann Hepatol. 2012;11:90-5.

5. Stevens LA, Coresh J, Greene T, Levey AS. Assessing kidney function--measured and estimated glomerular filtration rate. N Engl J Med. 2006;354:2473-83.

6. Proulx NL, Akbari A, Garg AX, Rostom A, Jaffey J, Clark HD. Measured creatinine clearance from timed urine collections substantially overestimates glomerular filtration rate in patients with liver cirrhosis: a systematic review and individual patient meta-analysis. Nephrol Dial Transplant. 2005;20:1617-22

7. Molitch ME, Rodman E, Hirsch CA, Dubinsky E. Spurious serum creatinine elevations in ketoacidosis. Ann Intern Med. 1980;93:280-1.

8. Soldin SJ, Henderson L, Hill JG. The effect of bilirubin and ketones on reaction rate methods for the measurement of creatinine. Clin Biochem. 1978;11:82-6.

9. de Carvalho JR, Villela-Nogueira CA, Luiz RR, Guzzo PL, da Silva Rosa JM, Rocha E, et al. Acute kidney injury network criteria as a predictor of hospital mortality in cirrhotic patients with ascites. J Clin Gastroenterol. 2012;46:e21-6.

10. Fagundes C, Barreto R, Guevara M, Garcia E, Sola E, Rodriguez E, et al. A modified acute kidney injury classification for diagnosis and risk stratification of impairment of kidney function in cirrhosis. J Hepatol. 2013;59:474-81.

11. Piano S, Rosi S, Maresio G, Fasolato S, Cavallin M, Romano A, et al. Evaluation of the acute kidney injury network criteria in hospitalized patients with cirrhosis and ascites. J Hepatol. 2013;59:482-9.

12. Wong F, O'Leary JG, Reddy KR, Patton H, Kamath PS, Fallon MB, et al. New consensus definition of acute kidney injury accurately predicts 30-day mortality in patients with cirrhosis and infection. Gastroenterology. 2013;145:1280-8.e1.

13. Terra C, Guevara M, Baccaro ME, Martin-Llahi M, Restuccia T, Torre A, et al. Relationship between renal function and serum creatinine levels in patients with cirrhosis. Relevance for prognosis assessment. J Hepatol. 2006;44:S94.

14. Chertow GM, Burdick E, Honour M, Bonventre JV, Bates DW. Acute kidney injury, mortality, length of stay, and costs in hospitalized patients. J Am Soc Nephrol. 2005;16:3365-70.

15. Tsien CD, Rabie R, Wong F. Acute kidney injury in decompensated cirrhosis. Gut. 2013;62:131-7.

16. Bellomo R, Ronco C, Kellum JA, Mehta RL, Palevsky P, Acute Dialysis Quality Initiative workgroup. Acute renal failure - definition, outcome measures, anima models, fluid therapy and information technology needs: the Second International Consensus Conference of the Acute Dialysis Quality Initiative (ADQI) Group. Crit Care. 2004;8:R204-212.

17. Mehta RL, Kellum JA, Shah SV, Molitoris BA, Ronco C, Warnock DG, et al. Acute Kidney Injury Network: report of an initiative to improve outcomes in acute kidney injury. Crit Care. 2007;11:R31.

18. Kidney Disease: Improving Global Outcomes (KDIGO) Acute Kidney Injury Work Group KDIGO Clinical Practice Guideline for Acute Kidney Injury. Kidney international 2012;2:1-138

19. Huelin P, Piano S, Sola E, Stanco M, Sole C, Moreira R, et al. Validation of a Staging system for acute kidney injury in patients with cirrhosis and association with acute-on-chronic liver failure. Clin Gastroenterol Hepatol. 2017;15: 438-445.e5.
20. Angeli P, Gines P, Wong F, Bernardi M, Boyer TD, Gerbes A, et al. Diagnosis and management of acute kidney injury in patients with cirrhosis: revised consensus recommendations of the International Club of Ascites. J Hepatol. 2015;62:968-74.

21. Fagundes C, Pepin MN, Guevara M, Barreto R, Casals G, Sola E, et al. Urinary neutrophil gelatinase-associated lipocalin as biomarker in the differential diagnosis of impairment of kidney function in cirrhosis. J Hepatol. 2012;57:267-73.

22. Ximenes RO, Farias AQ, Helou CM. Early predictors of acute kidney injury in patients with cirrhosis and bacterial infection: urinary neutrophil gelatinase-associated lipocalin and cardiac output as reliable tools. Kidney Res Clin Pract. 2015;34:140-5.

23. Ariza X, Sola E, Elia C, Barreto R, Moreira R, Morales-Ruiz M, et al. Analysis of a urinary biomarker panel for clinical outcomes assessment in cirrhosis. PLoS One. 2015;10:e0128145.

24. Elia C, Graupera I, Barreto R, Sola E, Moreira R, Huelin P, et al. Severe acute kidney injury associated with non-steroidal anti-inflammatory drugs in cirrhosis: A case-control study. J Hepatol. 2015;63:593-600.

25. Gines A, Escorsell A, Gines P, Salo J, Jimenez W, Inglada L, et al. Incidence, predictive factors, and prognosis of the hepatorenal syndrome in cirrhosis with ascites. Gastroenterology. 1993;105:229-36.

26. Iwakiri Y, Groszmann RJ. The hyperdynamic circulation of chronic liver diseases: from the patient to the molecule. Hepatology. 2006;43:S121-131.

27. Arroyo V, Terra C, Gines P. Advances in the pathogenesis and treatment of type-1 and type-2 hepatorenal syndrome. J Hepatol. 2007;46:935-46.

28. Esson ML, Schrier RW. Diagnosis and treatment of acute tubular necrosis. Ann Intern Med 2002;137:744-52.

29. Boyer TD, Sanyal AJ, Garcia-Tsao G, Blei A, Carl D, Bexon AS, et al. Predictors of response to terlipressin plus albumin in hepatorenal syndrome (HRS) type 1: relationship of serum creatinine to hemodynamics. J Hepatol. 2011;55:315-21.

30. Arroyo V, Gines P, Gerbes AL, Dudley FJ, Gentilini P, Laffi G, Reynolds TB, et al. Definition and diagnostic criteria of refractory ascites and hepatorenal syndrome in cirrhosis. International Ascites Club. Hepatology. 1996;23:164-76.

31. Mohanty A, Garcia-Tsao G. Hyponatremia and hepatorenal syndrome. Gastroenterol Hepatol (N Y). 2015;11:220-9.

32. Salerno F, Gerbes A, Gines P, Wong F, Arroyo V. Diagnosis, prevention and treatment of hepatorenal syndrome in cirrhosis. Gut. 2007;56:1310-8.

33. Bernardi M, Caraceni P, Navickis RJ, Wilkes MM. Albumin infusion in patients undergoing large-volume paracentesis: a meta-analysis of randomized trials. Hepatology. 2012;55:1172-81.

34. Garcia-Martinez R, Noiret L, Sen S, Mookerjee R, Jalan R. Albumin infusion improves renal blood flow autoregulation in patients with acute decompensation of cirrhosis and acute kidney injury. Liver Int. 2015;35:335-43.

35. Ortega R, Gines P, Uriz J, Cardenas A, Calahorra B, De Las Heras D, et al. Terlipressin therapy with and without albumin for patients with hepatorenal syndrome: results of a prospective, nonrandomized study. Hepatology. 2002;36:941-8.

36. Sort P, Navasa M, Arroyo V, Aldeguer X, Planas R, Ruiz-del-Arbol L, al. Effect of intravenous albumin on renal impairment and mortality in patients with cirrhosis and spontaneous bacterial peritonitis. N Engl J Med. 1999;341:403-9.

37. Salerno F, Navickis RJ, Wilkes MM. Albumin infusion improves outcomes of patients with spontaneous bacterial peritonitis: a meta-analysis of randomized trials. Clin Gastroenterol Hepatol. 2013;11:123-30.el

38. Guevara M, Terra C, Nazar A, Sola E, Fernandez J, Pavesi M, et al. Albumin for bacterial infections other than spontaneous bacterial peritonitis in cirrhosis. A randomized, controlled study. J Hepatol. 2012;57:759-65.

39. Thevenot T, Bureau C, Oberti F, Anty R, Louvet A, Plessier A, et al. Effect of albumin in cirrhotic patients with infection other than spontaneous bacterial peritonitis. A randomized trial. J Hepatol. 2015;62:822-30. 
40. Guevara M, Gines P, Fernandez-Esparrach G, Sort P, Salmeron JM, Jimenez $\mathrm{W}$, et al. Reversibility of hepatorenal syndrome by prolonged administration of ornipressin and plasma volume expansion. Hepatology. 1998;27:35-41.

41. Cavallin M, Kamath PS, Merli M, Fasolato S, Toniutto P, Salerno F, et al. Terlipressin plus albumin versus midodrine and octreotide plus albumin in the treatment of hepatorenal syndrome: A randomized trial. Hepatology. 2015;62:567-74.

42. Sanyal AJ, Boyer T, Garcia-Tsao G, Regenstein F, Rossaro L, Appenrodt B, Ble A, et al. A randomized, prospective, double-blind, placebo-controlled trial of terlipressin for type 1 hepatorenal syndrome. Gastroenterology. 2008;134:1360-8.

43. Martin-Llahi M, Pepin MN, Guevara M, Diaz F, Torre A, Monescillo A, et al Terlipressin and albumin vs albumin in patients with cirrhosis and hepatorenal syndrome: a randomized study. Gastroenterology. 2008;134:1352-9.

44. Gluud LL, Christensen K, Christensen E, Krag A. Systematic review of randomized trials on vasoconstrictor drugs for hepatorenal syndrome. Hepatology. 2010;51:576-84

45. Cavallin M, Piano S, Romano A, Fasolato S, Frigo AC, Benetti G, Gola E, et al. Terlipressin given by continuous intravenous infusion versus intravenous boluses in the treatment of hepatorenal syndrome: A randomized controlled study. Hepatology. 2016;63:983-992.

46. Singh V, Ghosh S, Singh B, Kumar P, Sharma N, Bhalla A, Sharma AK, et al. Noradrenaline vs. terlipressin in the treatment of hepatorenal syndrome: a randomized study. J Hepatol 2012;56:1293-1298.

47. Mattos AZ, Mattos AA, Ribeiro RA. Terlipressin versus noradrenaline in the treatment of hepatorenal syndrome: systematic review with meta-analysis and full economic evaluation. Eur J Gastroenterol Hepatol. 2016;28:345-51.

48. Mattos AZ, Mattos AA, Ribeiro RA. Terlipressin versus noradrenaline for hepatorenal syndrome. Economic evaluation under the perspective of the Brazilian Public Health System. Arq Gastroenterol. 2016;53:123-6.

49. Alessandria C, Venon WD, Marzano A, Barletti C, Fadda M, Rizzetto M. Rena failure in cirrhotic patients: role of terlipressin in clinical approach to hepatorenal syndrome type 2. Eur J Gastroenterol Hepatol. 2002;14:1363-8.

50. Belcher JM, Coca SG, Parikh CR. Creatinine change on vasoconstrictors as mortality surrogate in hepatorenal syndrome: systematic review \& meta-analysis PLoS One. 2015;10:e0135625.

51. Rodriguez E, Henrique Pereira G, Sola E, Elia C, Barreto R, Pose E, et al. Treatment of type 2 hepatorenal syndrome in patients awaiting transplantation: Effects on kidney function and transplantation outcomes. Liver Transpl. 2015;21:1347-54.
52. Ghosh S, Choudhary NS, Sharma AK, Singh B, Kumar P, Agarwal R, Sharma $\mathrm{N}$, et al. Noradrenaline vs terlipressin in the treatment of type 2 hepatorenal syndrome: a randomized pilot study. Liver Int. 2013;33:1187-93.

53. Testino G, Ferro C, Sumberaz A, Messa P, Morelli N, Guadagni B, et al. Type-2 hepatorenal syndrome and refractory ascites: role of transjugular intrahepatic portosystemic stent-shunt in eighteen patients with advanced cirrhosis awaiting orthotopic liver transplantation. Hepatogastroenterology. 2003;50:1753-5.

54. Rossle M, Gerbes AL. TIPS for the treatment of refractory ascites, hepatorenal syndrome and hepatic hydrothorax: a critical update. Gut. 2010;59: 988-1000.

55. Tan HK, Marquez M, Wong F, Renner EL. Pretransplant type 2 hepatorenal syndrome is associated with persistently impaired renal function after liver transplantation. Transplantation. 2015;99:1441-6.

56. Ricci Z, Ronco C, D’Amico G, De Felice R, Rossi S, Bolgan I, et al. Practice patterns in the management of acute renal failure in the critically ill patient: an international survey. Nephrol Dial Transplant. 2006;21:690-6.

57. Doshi M, Murray PT. Approach to intradialytic hypotension in intensive care unit patients with acute renal failure. Artif Organs. 2003;27:772-80.

58. Murray P, Hall J. Renal replacement therapy for acute renal failure. Am J Respir Crit Care Med. 2000;162:777-81.

59. Garg N, Fissell WH. Intradialytic hypotension: a case for going slow and looking carefully. Nephrol Dial Transplant. 2013;28:247-9.

60. Uchino S, Ronco C: Continous Renal Replacement Theraphy. In: Jorres A, Ronco C, Kellum JA, eds. Management of Acute Kidney Problems. 1st Edition ed. New York: Springer; 2010, p.525-35.

61. Gonwa TA, Klintmalm GB, Levy M, Jennings LS, Goldstein RM, Husberg BS Impact of pretransplant renal function on survival after liver transplantation. Transplantation. 1995;59:361-5.

62. Nair S, Verma S, Thuluvath PJ. Pretransplant renal function predicts survival in patients undergoing orthotopic liver transplantation. Hepatology. 2002;35:11791185

63. Eason JD, Gowa TA, Davis CL, Sung RS, GerberD, Bloom RD. Proceedings of consensus conference on simultaneous liver-kidney transplantation (SLK). Am J Transplant. 2008;8:2243-51.

64. Nadim MK, Sung RS, Davis CL, Andreoni KA, Biggins SW, Danovitch GM, et al. Simultaneous liver-kidney transplantation summit: current state and future directions. Am J Transplant. 2012;12:2901-2908. 